\title{
Analysing the efficacy of the I-gel supraglottic airway device in the supine and lateral decubitus positions
}

\author{
Kemal Tolga Saracoglu ${ }^{1}$, Ali Demir ${ }^{2}$, Gokhan Pehlivan ${ }^{3}$, Ayten Saracoglu ${ }^{3}$, Zeynep Eti ${ }^{2}$ \\ ${ }^{1}$ Department of Anaesthesiology and Intensive Care, Istanbul Bilim University Medical School, Istanbul, Turkey \\ ${ }^{2}$ Department of Anaesthesiology and Intensive Care, Istanbul Baskent University Medical School, \\ Istanbul, Turkey \\ ${ }^{3}$ Department of Anaesthesiology and Intensive Care, Istanbul Marmara University Medical School, \\ Istanbul, Turkey
}

\begin{abstract}
Background: The advantages of the I-gel supraglottic airway device include ease and speed of insertion, reduced trauma incidence, an integral bite block, gastric access, a non-inflatable cuff and superior seal pressure. The primary goal of this study was to compare airway leak pressures and the fibreoptic view in the supine and lateral positions. Our secondary aim was to analyse the effects of I-gel insertion on haemodynamic parameters.

Methods: One hundred patients undergoing saturation biopsy due to prostatic hyperplasia were recruited to this prospective randomised study. An I-gel device was inserted in the supine position. Taking of measurements, patients were placed in the lateral decubitus position. Mean arterial pressure, heart rate, peripheral $\mathrm{O}_{2}$ saturation and end-tidal $\mathrm{CO}_{2}$ were recorded before and after insertion. We recorded the number of attempts and insertion time for the l-gel device. Oropharyngeal leak pressures and l-gel device positioning were scored in the lateral decubitus and supine positions. Results: It was possible to insert the l-gel device in 88 patients on the first attempt. The median time for insertion was $7.97 \pm 2.18 \mathrm{sec}$. The mean arterial pressure and heart rate decreased 1 and $2 \mathrm{~min}$ after insertion. Oropharyngeal leak pressure was similar in the supine $(27.45 \pm 5.37 \mathrm{~mm} \mathrm{Hg})$ and lateral decubitus positions $(26.04 \pm 4.92 \mathrm{~mm} \mathrm{Hg})$ $(P>0.05)$. On fibreoptic examination through the l-gel device, the scores of patients were comparable in different positions $(P=0.542)$.

Conclusion: As there was no significant difference in oropharyngeal leak pressure and fibreoptic view, we concluded that the I-gel device may be used safely in both the supine and lateral positions.
\end{abstract}

Anaesthesiology Intensive Therapy 2018, vol. 50, no 4, 259-262

Key words: airway device, I-gel; airway device, insertion; positioning

Supraglottic airway devices (SADs), having various advantages such as ease of fit, haemodynamic stability, positive respiratory mechanics and reduced airway morbidity, have a well-established use [1]. Displacement-related compression or trauma risk is significantly low [2]. The l-gel device is quick, easy and consistently reliable to insert [3]. Its non-inflatable cuff, bite-block and gastric drainage channel are the superior features of the l-gel device [4]. Having up to $30 \mathrm{~mm} \mathrm{Hg}$ pharyngeal seal leak pressure, it provides as many ventilation characteristics as a tracheal tube can offer $[5,6]$.
The large oval structure of I-gel allows buccal stabilisation and reduces the risk for axial rotation and malposition [7]. Although such advantages of ventilation with the I-gel device are well documented, the effects of body position changes on the device have not been evaluated.

The efficacy of ventilation with SADs changes according to head and neck positions [8-10]. The primary aim of this study was to compare airway leak pressure and fibreoptic view in the supine and lateral positions. Our secondary aim was to analyse the effects of I-gel insertion on haemodynamic parameters. 


\section{METHODS}

Following the approval of the Ethics Committee and the securing of patients' written informed consents, 100 ASA 1-3 patients above 18 years of age, undergoing saturation biopsy due to prostatic hyperplasia were included in the study. Exclusion criteria included patients with neck or upper airway pathologies and regurgitation of stomach contents or pulmonary aspiration risk. All the anaesthesiologists were experienced in using the l-gel device.

Although we administered $1-3 \mathrm{mg} \mathrm{kg}^{-1}$ propofol and $1 \mathrm{\mu g} \mathrm{kg}^{-1}$ remifentanil iv, we did not use any muscle relaxant. When patients were unresponsive to anterior jaw thrust and their eyelash reflexes disappeared, the level of anaesthesia was considered appropriate for I-gel insertion [11]. In anticipation of having difficulty opening the patient's mouth, gagging or coughing, we administered an additional dose of iv propofol ( $20 \mathrm{mg}$ ).

The l-gel device was inserted according to the manufacturer's instructions. Before insertion, the front and back sides of the device were lubricated with a water-based lubricant. We used adult-size 3, 4 or 5 I-gel devices according to the patients' weight. We recorded the number of attempts and the time required for insertion. When we had problems related to insertion, we applied various adjuvant manoeuvres. We used techniques such as head flexion or extension, or slightly pulling or pushing the device. We recorded any additional manoeuvres. The success of the ventilation was determined based on visible chest movements, a square wave capnogram, the provision of tidal volume expired above $7 \mathrm{~mL} \mathrm{~kg}^{-1}$ and $\mathrm{SpO}_{2}$ above $95 \%$. When insertion or ventilation failed three times in succession, patients were ventilated using a Laryngeal Mask Airway (LMA) Classic. The I-gel device was inserted in the supine position. Blood pressure, heart rate, $\mathrm{SpO}_{2}$ and end tidal $\mathrm{CO}_{2}$ values of patients were recorded before and after insertion. The measurements were repeated in the following $1^{\text {st }}$ and $2^{\text {nd }}$ minutes. The position of the l-gel device was evaluated with a fibreoptic bronchoscope passing through the device. The bronchoscope was pushed forward up to $1 \mathrm{~cm}$ proximal of the l-gel device and the obtained glottic view scored as follows [12]: only vocal cords can be seen - 4 points; vocal cords and posterior epiglottis can be seen - 3 points; vocal cords and anterior epiglottis can be seen -2 points; vocal cords cannot be seen -1 point.

In order to measure the airway leak pressure, ventilation was halted by closing the anaesthetic circuit to the atmosphere. The rise in the airway circuit was recorded using $5 \mathrm{~L}$ $\mathrm{min}^{-1}$ fresh gas flow until an audible leak occurred or the airway pressure increased and plateaued. The pressure was allowed to reach $40 \mathrm{~cm} \mathrm{H}_{2} \mathrm{O}$ at maximum [13]. Afterward, the patients were placed in the lateral decubitus position and after the $1^{\text {st }}$ and $2^{\text {nd }}$ minutes, their haemodynamic data, $\mathrm{SpO}_{2}$, and $\mathrm{CO}_{2}$ values were measured and the fibreoptic view was obtained for each patient. Surgery could be commenced only after all these measurements had been completed. The oropharyngeal leak pressure was measured in both positions. Data regarding the presence of blood or secretion on the I-gel device, or the occurrence of any complication, were noted. Patients were followed up during the first postoperative 24 hours to monitor any throat, chin or neck pain.

\section{STATISTICAL ANALYSIS}

One hundred patients were considered sufficient for the study when the difference between oropharyngeal leak pressures of the supine and lateral positions was accepted max. $2 \mathrm{~mm} \mathrm{Hg}$ with a standard deviation of $5 \mathrm{~mm} \mathrm{Hg}$, alpha= 0.05 , beta $=0.8$. The standard effect size was assumed to be 0.40 .

Statistical analyses were conducted using the SPSS program version 21.0. The mean, standard deviation, ratio, and frequency values were used for the descriptive statistics of the data. The distribution of variables was tested using the Kolmogorov-Smirnov test. Quantitative data was analysed with the paired-sample t-test and the Wilcoxon test while the qualitative data was analysed using McNemar's test. $P$ $<0.05$ was considered statistically significant.

\section{RESULTS}

One hundred and ten male patients meeting the inclusion criteria were included to the study. Two of them did not give their approval to participate in the study while 8 other patients could not be ventilated efficiently with the I-gel device. In total, data for 100 patients were statistically analysed. The median age was 65 years (range 44 to 84 years) while the median body mass was $81 \mathrm{~kg}$ (range 50 to $110 \mathrm{~kg}$ ). We obtained 24 prostate biopsies from all patients in the lateral decubitus position.

There no significant difference between patients regarding their demographic data (Table 1). The average time required for $\mathrm{l}$-gel insertion was $7.97 \pm 2.18$ seconds. It was possible to insert the l-gel device in 9 patients on the $2^{\text {nd }}$ attempt, and in 3 patients on the $3^{\text {rd }}$ attempt. The mean arterial pressure and heart rate in the supine position during the $1^{\text {st }}$ and $2^{\text {nd }}$ minutes of the preoperative period was significantly higher than the measurements conducted in the lateral decubitus position $(P<0.05)$. There was no significant difference between two positions in terms of peripheral oxygen saturation and end tidal $\mathrm{CO}_{2}$ values (Table 2 ).

While the median oropharyngeal leak pressure was found to be $27.45 \pm 5.37 \mathrm{~mm} \mathrm{Hg}$ in the supine position, it was $26.04 \pm 4.92 \mathrm{~mm} \mathrm{Hg}$ in the lateral decubitus position $(P>0.05)$. The fibreoptic view through the I-gel device did not indicate any difference between two positions ( $P=0.542$, Table 3). Although we identified blood on the I-gel device in 
Table 1. Patients' demographics (mean \pm SD). No significant differences were confirmed

\begin{tabular}{ll}
\hline Age (years) & $65.16 \pm 7.56$ \\
Body mass $(\mathrm{kg})$ & $81.28 \pm 10.77$ \\
Height $(\mathrm{cm})$ & $169.5 \pm 29.61$ \\
\hline
\end{tabular}

Table 2. Comparison of perioperative parameters in supine position (mean \pm SD)

\begin{tabular}{llll}
\hline & & Supine & $P$-value \\
\hline Mean arterial & $\mathrm{T}_{1}$ & $91.89 \pm 16.33$ & \\
pressure $(\mathrm{mm} \mathrm{Hg})$ & $\mathrm{T}_{2}$ & $84.35 \pm 12.84$ & $<0.05$ \\
& $\mathrm{~T}_{3}$ & $79.39 \pm 13.02$ & $<0.05$ \\
Heart rate $\left(\mathrm{min}^{-1}\right)$ & $\mathrm{T}_{1}$ & $78.52 \pm 11.44$ & \\
& $\mathrm{~T}_{2}$ & $74.98 \pm 11.60$ & $<0.05$ \\
& $\mathrm{~T}_{3}$ & $73.65 \pm 11.77$ & $<0.05$ \\
Peripheral $\mathrm{O}_{2}$ & $\mathrm{~T}_{1}$ & $99.00 \pm 1.05$ & 0.262 \\
saturation $(\%)$ & $\mathrm{T}_{2}$ & $98.83 \pm 1.08$ & 0.051 \\
& $\mathrm{~T}_{3}$ & $98.56 \pm 1.08$ & 0.183 \\
End tidal $\mathrm{CO}_{2}$ & $\mathrm{~T}_{1}$ & $32.90 \pm 2.51$ & 0.128 \\
(mm $\mathrm{Hg})$ & $\mathrm{T}_{2}$ & $32.43 \pm 2.43$ & 0.226 \\
& $\mathrm{~T}_{3}$ & $31.70 \pm 2.49$ & 0.106 \\
\hline
\end{tabular}

$\mathrm{T}_{1}$ : Before induction

$\mathrm{T}_{2}: 1$. min after insertion

$\mathrm{T}_{3}: 2$. min after insertion

two patients, once it had been pulled out, we did not come across any other complications. No significant complaint was observed for the presence of throat pain. None of the patients required additional analgesics.

\section{DISCUSSION}

In this prospective clinical trial, we analysed the efficacy of the I-gel supraglottic airway device on 100 individuals undergoing prostate biopsy without a muscle relaxant. There was no significant difference in oropharyngeal leak pressure and fibreoptic view when the patient's position was changed from supine to lateral while patients could be ventilated with a sufficient amount of tidal volume.

The I-gel device was well tolerated by patients both during anaesthesia and emergence from anaesthesia. Therefore, using the l-gel device in patients under anaesthesia, both for controlled ventilation and spontaneous breathing, seems to be appropriate. In this study, the successful insertion rate for the I-gel device was $92 \%, 88 \%$ of which was inserted successfully on the first attempt. The I-gel device provided airway approximately in 8 seconds. As the anaesthesiologists taking part in the study comprised experienced anaesthetists using the l-gel device frequently in practice, this factor may have increased the speed and success of insertion. In a previous study carried out with
Table 3. Evaluation of the I-gel device position using fibreoptic bronchoscope passing through the I-gel device

\begin{tabular}{lcc}
\hline Scores & Supine & Lateral decubitus \\
\hline 1 & $\mathrm{n}=4(4.0 \%)$ & $\mathrm{n}=5(5.1 \%)$ \\
2 & $\mathrm{n}=21(21.2 \%)$ & $\mathrm{n}=15(15.2 \%)$ \\
3 & $\mathrm{n}=44(44.4 \%)$ & $\mathrm{n}=49(49.5 \%)$ \\
4 & $\mathrm{n}=30(30.3 \%)$ & $\mathrm{n}=30(30.3 \%)$ \\
\hline
\end{tabular}

anaesthetists who were inexperienced in l-gel insertion and who placed the l-gel device after 10 attempts, the median time required for ventilation was reported approximately 15 seconds [11]. However, another study has asserted the contrary by stating that one's experience has no impact, either on the time to achieve ventilation or the success rate of insertion [2]. Nevertheless, as the latter is a manikin study, its results should be supported with more clinical trials before being adopted into clinical practice. On the other hand, the I-gel device was applied both on manikins and patients in another study while the insertion time differed by approximately 3.5 seconds between two groups [14].

While the mean leak pressure was measured at $27.4 \mathrm{~mm}$ $\mathrm{Hg}$ in the supine position, this figure decreased to $26.0 \mathrm{~mm}$ $\mathrm{Hg}$ in the lateral decubitus position. However, this decrease did not create any clinical difficulty in ventilation and patients could be continuously ventilated. Patients were evaluated according to the data on sufficiency of tidal volume, appropriate chest movements and stable oxygen saturation. Considering that the mean leak pressure obtained in previous studies from the patients placed in the supine position was $23.7 \mathrm{~mm} \mathrm{Hg}$ [15] or $20 \mathrm{~mm} \mathrm{Hg} \mathrm{[16],} \mathrm{the} \mathrm{leak} \mathrm{pressure}$ obtained from our study is higher. However, unlike other studies, our study compared the supine and lateral positions. To the best of our knowledge, this is the first study comparing the efficacy of the l-gel device in the supine and lateral decubitus positions regarding patients receiving general anaesthesia without any muscle relaxant. Sanuki et al. [8] conducted a study on various head positions. As their 20-patient series indicated that head and neck flexion has more negative effects on ventilation scores as compared to the neutral position, it was argued in the same study that flexion should be avoided for patients ventilated with the I-gel device. In contrast to this study, we did not come across any significant difficulty in ventilating patients receiving a little head and neck flexion in the lateral decubitus position.

The mean arterial pressure and heart rate at $1^{\text {st }}$ and $2^{\text {nd }}$ minutes after l-gel insertion were found to be significantly lower in the supine position. We concluded that it corresponds to the time when sufficient depth of anaesthesia was provided for the patient. 
In line with the data in the literature [17], the I-gel device was inserted with a high success rate on the first attempt in our study. Contrary to the suggestion made by Amini and Khoshfetrat [18], we made a third attempt for the patients who could not be ventilated with the I-gel device on the $1^{\text {st }}$ and $2^{\text {nd }}$ attempts. Thus, it was possible to ventilate three patients successfully on the $3^{\text {rd }}$ attempt using the I-gel device. However, all patients who could not be ventilated with I-gel device were ventilated using the Laryngeal Mask Airway Classic; therefore, we did not need to apply another SAD or tracheal intubation. Even though all the anaesthetists were experienced in I-gel insertion, they had more experience with the LMA classic. We believe that their experience with the LMA classic contributed to the successful provision of the airway with the LMA device in patients who could not be ventilated using the I-gel device.

Analysing the fibreoptic view through the I-gel device provided an acceptable view of the vocal cords. The view of vocal cords was at the level of Grade 3 and 4 for $74 \%$ of the patients in the supine position and $79 \%$ of the patients in the lateral decubitus position. According to the size of these rates we concluded that the I-gel device may be used comfortably in different anatomical positions. On the other hand, there should be further studies including more subjects to properly reflect these data into clinical practice.

\section{LIMITATIONS}

This study has some limitations which need to be stated. As the study population was composed of only male patients, it cannot provide information on females. Additionally, although sore throat and discomfort have been reported to be more common in females, there is no evidence supporting the idea that gender affects the success rate or leak pressure [19].

\section{CONCLUSION}

The results of the study suggest that the I-gel device is an airway device offering reliable and quick insertion. As there was no significant difference in oropharyngeal leak pressure and fibreoptic view, we concluded that the I-gel device may be used safely in both the supine and lateral positions.

\section{ACKNOWLEDGEMENTS}

1. Source of funding: none.

2. Conflict of interest: none.

3. The abstract of this study was selected as the best abstract presentation at the $2^{\text {nd }}$ European Airway Management Congress.

\section{References:}

1. Sharma B, Sehgal R, Sahai C, et al.PLMA vs. I-gel: A comparative evaluation of respiratory mechanics in laparoscopic cholecystectomy. J Anaesthesiol Clin Pharmacol. 2010; 26(4): 451-457, indexed in Pubmed: 21547168.
2. Gatward JJ, Thomas MJC, Nolan JP, et al. Effect of chest compressions on the time taken to insert airway devices in a manikin. $\mathrm{Br} J$ Anaesth. 2008; 100(3):351-356, doi: 10.1093/bja/aem364, indexed in Pubmed: 18158311.

3. Hughes $\mathrm{C}$, Place $\mathrm{K}$, Berg S, et al. A clinical evaluation of the I-gel ${ }^{\mathrm{TM}}$ supraglottic airway device in children. Paediatr Anaesth. 2012; 22(8): 765-771, doi: 10.1111/j.1460-9592.2012.03893.x, indexed in Pubmed: 22672411.

4. Ragazzi R, Finessi L, Farinelli I, et al. LMA Supreme ${ }^{T M} v s$ i-gel ${ }^{T M}$ - a comparison of insertion success in novices. Anaesthesia. 2012; 67(4): 384-388, doi: 10.1111/j.1365-2044.2011.07002.x, indexed in Pubmed: 22329593.

5. Uppal V, Fletcher G, Kinsella J. Comparison of the i-gel with the cuffed tracheal tube during pressure-controlled ventilation. $\mathrm{Br} J$ Anaesth. 2009; 102(2): 264-268, doi: 10.1093/bja/aen366, indexed in Pubmed: 19151051.

6. Bamgbade OA, Macnab WR, Khalaf WM. Evaluation of the i-gel airway in 300 patients. Eur J Anaesthesiol. 2008; 25(10): 865-866, doi: 10.1017/ S0265021508004511, indexed in Pubmed: 18534042.

7. Kannaujia A, Srivastava U, Saraswat N, et al. A preliminary study of I-gel: a new supraglottic airway device. Indian J Anaesth. 2009; 53(1): 52-56, indexed in Pubmed: 20640078.

8. Sanuki T, Uda R, Sugioka S, et al. The influence of head and neck position on ventilation with the i-gel airway in paralysed, anaesthetised patients. Eur J Anaesthesiol. 2011; 28(8): 597-599, doi: 10.1097/EJA .0b013e32834698f4, indexed in Pubmed: 21505345.

9. Park SH, Han $\mathrm{SH}, \mathrm{Do} \mathrm{SH}$, et al. The influence of head and neck position on the oropharyngeal leak pressure and cuff position of three supraglottic airway devices. Anesth Analg. 2009; 108(1): 112-117, doi: 10.1213/ ane.0b013e318192376f, indexed in Pubmed: 19095838.

10. Kim JT, Na HS, Bae JY, et al. Flexion compromises ventilation with the laryngeal tube suction II in children. Paediatr Anaesth. 2009; 19(2): 153-158, doi: 10.1111/j.1460-9592.2008.02861.x, indexed in Pubmed: 19143960.

11. Gatward JJ, CookTM, Seller C, et al. Evaluation of the size 4 i-gel airway in one hundred non-paralysed patients. Anaesthesia. 2008;63(10):1124-1130, doi: 10.1111/j.1365-2044.2008.05561.x, indexed in Pubmed: 18616521.

12. Francksen $\mathrm{H}$, Renner $\mathrm{J}$, Hanss $\mathrm{R}$, et al. $\mathrm{A}$ comparison of the $\mathrm{i}$-gel with the LMA-Unique in non-paralysed anaesthetised adult patients. Anaesthesia. 2009; 64(10): 1118-1124, doi: 10.1111/j.1365-2044.2009.06017.x, indexed in Pubmed: 19735404.

13. Lopez-Gil M, Brimacombe J, Garcia G. A randomized non-crossover study comparing the ProSeal and Classic laryngeal mask airway in anaesthetized children. Br J Anaesth. 2005; 95(6): 827-830, doi: 10.1093/bja/aei234, indexed in Pubmed: 16210311.

14. Wharton NM, Gibbison B, Gabbott DA, et al. I-gel insertion by novices in manikins and patients. Anaesthesia. 2008; 63(9): 991-995, doi: 10.1111/j.1365-2044.2008.05542.x, indexed in Pubmed: 18557971.

15. Weber U, Oguz R, Potura LA, et al. Comparison of the i-gel and the LMA-Unique laryngeal mask airway in patients with mild to moderate obesity during elective short-term surgery. Anaesthesia. 2011; 66(6): 481-487, doi: 10.1111/j.1365-2044.2011.06682.x, indexed in Pubmed: 21568982.

16. Janakiraman $\mathrm{C}$, Chethan DB, Wilkes AR, et al. A randomised crossover trial comparing the i-gel supraglottic airway and classic laryngeal mask airway. Anaesthesia. 2009; 64(6): 674-678, doi: 10.1111/j.1365-2044.2009.05898.x, indexed in Pubmed: 19453322.

17. Theiler LG, Kleine-Brueggeney M, Kaiser D, et al. Crossover comparison of the laryngeal mask supreme and the i-gel in simulated difficult airway scenario in anesthetized patients. Anesthesiology. 2009; 111(1): 55-62, doi: 10.1097/ALN.0b013e3181a4c6b9, indexed in Pubmed: 19512881.

18. Amini S, KhoshfetratM.Comparison of the Intersurgical Solus laryngeal mask airway and the i-gel supralaryngeal device. Anaesthesia. 2010; 65(8): 805809, doi: 10.1111/j.1365-2044.2010.06336.x, indexed in Pubmed: 20560920.

19. Richez B, Saltel L, Banchereau F, et al. A new single use supraglottic airway device with a noninflatable cuff and an esophageal vent: an observational study of the i-gel. Anesth Analg. 2008; 106(4): 1137-9, table of contents, doi: 10.1213/ane.0b013e318164f062, indexed in Pubmed: 18349185.

\section{Corresponding author:}

Kemal Tolga Saracoglu, Assoc. Prof. M.D.

Department of Anaesthesiology,

Istanbul Bilim University School of Medicine,

Sisli Florence Nightingale Hospital, Istanbul, Turkey

e-mail: saracoglukt@gmail.com

Received: 15.02 .2017

Accepted: 5.09.2018 